\title{
GROWTH-RELATED ORDER OF THE RETINAL FIBER LAYER IN GOLDFISH $^{1}$
}

\author{
STEPHEN S. EASTER, JR., ${ }^{2}$ BRADFORD BRATTON, AND STEVEN S. SCHERER \\ Division of Biological Sciences, University of Michigan, Ann Arbor, Michigan 48109-1048
}

Received December 13, 1983; Revised February 2, 1984; Accepted February 3, 1984

\begin{abstract}
The retinal tiber layer and the juxtaretinal portion of the optic nerve of goldfish have been studied with light and electron microscopy in order to determine whether the age-related order of fibers in the nerve originates in the retina.

In the retina, no patent spaces (channels) were noted. The fibers ran in fascicles and consisted of two classes: nonmyelinated fibers, which ran superficially (close to the vitreal surface), and "myelinated" fibers, which ran more deeply and were loosely wrapped by processes presumed to be glial. The myelinated fibers were larger and presumably older. The nonmyelinated fibers are believed to be the young ones, from the peripheral, more recently generated, ganglion cells, for the following reasons. (1) Their size and cytoskeletal elements were typical of young axons. (2) They were the only axons in peripheral retina. (3) They were continuous with the nonmyelinated fibers in the nerve, previously shown to be the young ones. (4) When retinal axons were cut peripherally, the degenerating axons were in the superficial part of the fiber layer. (5) Growth cones, presumably from the newest ganglion cells, were always observed at the most superficial position in the fiber layer, in direct contact with the basal lamina of the inner limiting membrane superficially and nonmyelinated fibers deeply.

The nonmyelinated fibers always clustered together in the retinal fiber layer and occupied the most central portion in the cross-section of the optic nerve head. Thus, the age-related organization of fibers in the nerve is established in the retina.

These results are discussed in the context of growth, with the aim of evaluating the relative importance of four factors that might influence the intraretinal course of the growth cone. Its interactions with other fibers and with the basal lamina of the inner limiting membrane seem to be more important than interactions with the glial end feet or guidance into open, preformed channels.
\end{abstract}

The retina of teleosts grows by adding new neurons, including ganglion cells, at the retinal margin (Müller, 1952; Johns, 1977; Meyer, 1978). As a result, each generation of ganglion cells occupies an anulus roughly centered on the optic disk. Because this neurogenesis continues throughout life, producing 40 to 50 new ganglion cells daily, there are always new axons which must find their way from the retina through the optic nerve and tract into the tectum (Easter et al., 1981). Recent anatomical work has shown that axons of the same generation course together in the optic nerve and tract (Scholes, 1979; Rusoff and Easter, 1980; Bunt, 1982) and in the fascicles of the stratum opticum in the tectum (Stuermer and Easter, 1984).

The fact that axons from a common retinal anulus course together outside the retina is difficult to reconcile with their apparent organization in the retina, where the axons course

\footnotetext{
${ }^{1}$ We thank Drs. P. A. Raymond, C. A. O. Stuermer, and P. Hitchcock for useful discussion, Dr. T. Ogden for sharing his methods of fixation with us, and Dr. P. Hitchcock for allowing us to photograph one of his whole mounted retinas. This work was supported by National Institutes of Health Grants EY-00168 (to S. S. E.) and EY-07022 (to S. S. S.).

${ }^{2}$ To whom correspondence should be addressed.
}

like the spokes of a wheel from their somata of origin toward the optic disk. Therefore, any axon passes over ganglion cells of previous generations and joins fascicles made up of older axons. How does each generation of new axons join those from different sectors but of the same anulus?

In this paper, we attempt to answer this question by examining the retinal fiber layer in goldfish. In the process of doing so, we have also identified the axonal growth cones, and we describe them as well.

Part of this work has previously appeared in abstracts (Bratton et al., 1983; Easter et al., 1983).

\section{Materials and Methods}

Common goldfish, 8 to $12 \mathrm{~cm}$ standard length, were obtained commercially and maintained in aerated aquaria. All surgical procedures, including sacrifice, were carried out after anesthetizing the fish by immersion in aqueous $0.1 \%$ tricaine methanesulfonate.

Intraretinal fibers and ganglion cells were labeled with horseradish peroxidase (HRP; Miles type 6 ) by cutting the optic nerve intraorbitally and applying an HRP-soaked fragment of Gelfoam to the cut end. After 2 to 3 days, the animal was dark adapted, to facilitate the removal of the retina, and was decapitated. The retina was dissected from the pigmented epithelium, fixed in phosphate-buffered glutaraldehyde, and 
reacted for HRP according to the method of Adams (1977). Then it was either osmicated for electron microscopy (see next paragraph) or dehydrated, cleared in xylene, and mounted in Permount, vitreal surface up, under a coverslip.

The retina and part of the optic nerve were prepared for electron microscopy following fixation by immersion. The eye, along with a small stump of the optic nerve, was removed, and the cornea, iris, and lens were cut away. Usually the eye cup was immersed for $2 \mathrm{hr}$ at room temperature in buffered prefixative $(3.2 \%$ glutaraldehyde, $0.001 \mathrm{M}$ $\mathrm{CaCl}_{2}, 7.5 \%$ sucrose, in $0.05 \mathrm{M}$ sodium cacodylate buffer of $\mathrm{pH}=7.0$ to 7.4 ), rinsed in buffer, and postfixed in similarly buffered $2 \% \mathrm{OsO}_{4}$. The retinal myelinated fibers (see "Results") were best preserved with an alternative procedure, suggested to us by Dr. Thomas Ogden. The eye was removed, trimmed as above, and cut with four equally spaced, radial cuts that extended from the margin most of the way to the optic disk. Then the eye cup was pinned flat with broken glass micropipettes onto paraffin and was flooded with an ice-cold pre-prefixative made moments earlier $\left(2 \%\right.$ glutaraldehyde, $2 \%$ paraformaldehyde, $0.1 \% \mathrm{OsO}_{4}$, in $0.05 \mathrm{M}$ phosphate buffer) for $15 \mathrm{~min}$. The tissue was then prefixed for an hour or more in similar, ice-cold fixative in which the concentration of $\mathrm{OsO}_{4}$ was $1.0 \%$. Then it was rinsed in buffer, fixed in phosphate-buffered $2 \% \quad \mathrm{OsO}_{4}$ without aldehydes, rinsed in distilled water, dehydrated through graded ethanols, cleared in propylene oxide, and embedded in Epon.

Semithin sections (1-2 $\mu \mathrm{m}$ ) were mounted on glass microscope slides, stained with toluidine blue, and examined light microscopically in a Wild M-20 microscope equipped for photography. Ultrathin sections (silver to gray interference colors) were mounted on uncoated mesh grids or Formvar-coated, one-hole grids, stained with uranyl and lead salts, and examined in a Philips 300 electron microscope. Photomosaics of overlapping prints (typically $\times 9000$ ) were sometimes constructed to allow examination of large fields away from the microscope. Calibrations were established with a stage micrometer (light microscopy) and a grating replica (electron microscopy).
In order to cause the axons of peripheral retinal ganglion cells to degenerate, they were severed by a razor cut through the outside of the eye, parallel and close to the retinal margin. The effectiveness of the cut was assessed, first, by noting that the blade extended into the vitreous and, later, by locating the lesion in the fixed retina. After 4 days, the lesioned retinas were prepared for electron microscopy. A wedge, pointed end at the optic disk, wide end at the retinal margin and including the lesion and flanking unlesioned areas, was cut from the retina and embedded. The embedded tissue was subsequently examined electron microscopically for degenerating fibers.

\section{Results}

The light micrograph of Figure 1 shows the HRP-labeled ganglion cells and fibers in a retinal whole mount, about midway between the optic disk and the margin. The fibers do not cover the retina uniformly but are gathered into fascicles tens of micrometers wide, which converge on the optic disk far to the left of this picture. Individual fascicles, such as $\mathrm{f} 1$ and $\mathrm{f} 2$, merge to form a larger one, f3. Although fibers tend to run along spokes close to their somata of origin, many that seem to arise close to one fascicle course obliquely away from this one to join another. Single fibers occasionally form hair-pin loops, as if their initial outgrowth was toward the margin but later reversed. Thus, while the fibers generally course directly from soma to disk, there is some local wandering. Fibers have rarely been seen to course long distances in the tangential direction (parallel to the retinal margin) before turning sharply and entering the disk in a fascicle far removed from their sector of origin. Cook (1982) has previously described such fibers in the goldfish retina, and we have confirmed his results, through experiments very similar to his.

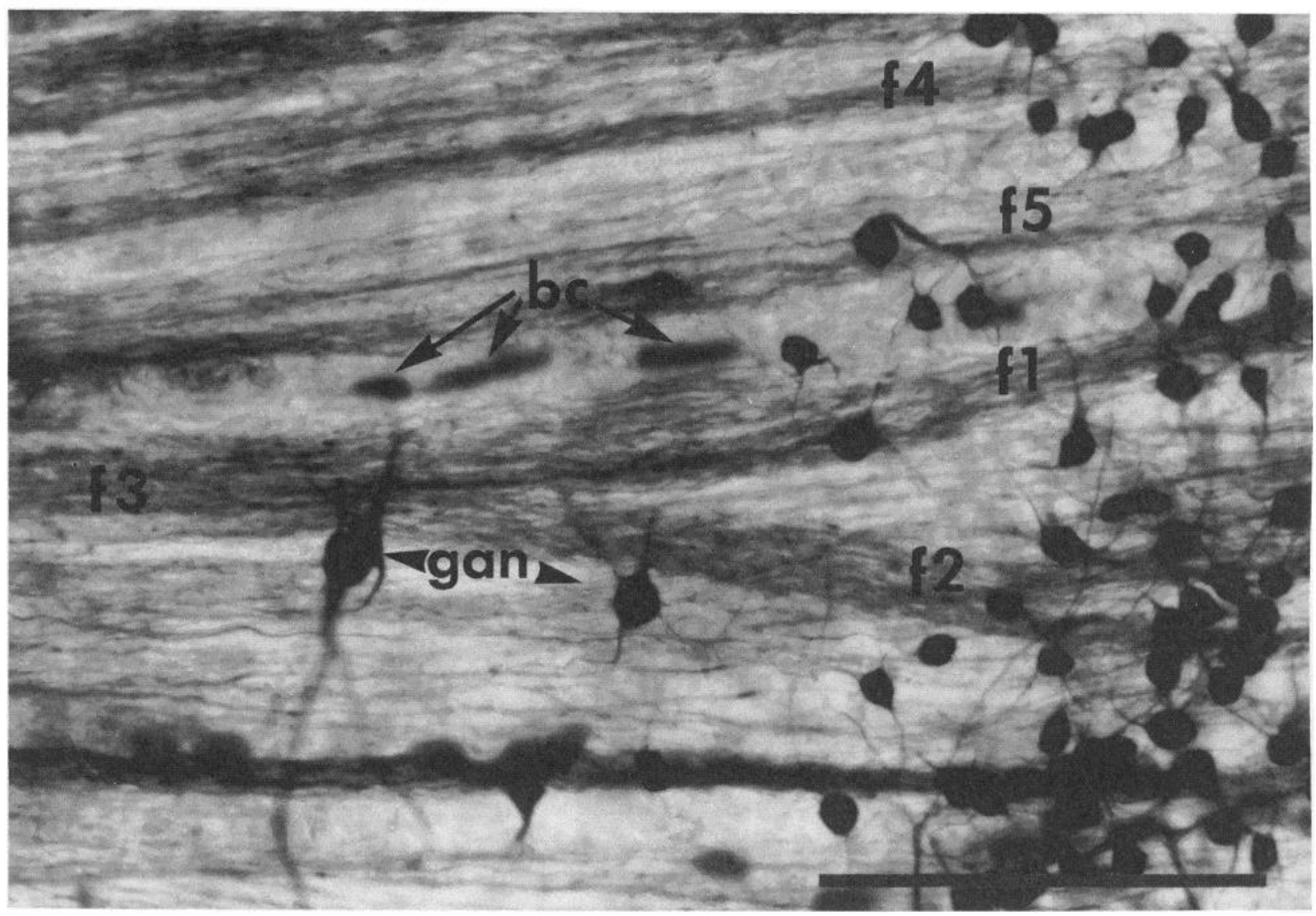

Figure 1. Retinal whole mount. The optic nerve head is to the left, and the retinal margin is to the right. The retrogradely transported HRP labeled an anulus of cell bodies and spared most of those close to the optic nerve head, permitting an unobstructed view of the fascicles $(f)$ in the left half of this micrograph. Two ganglion cell somata (gan) are indicated. Blood cells (bc) in the superficial hyaloid vessels stained heavily but lie out of the plane of focus. Tissue was prepared by Dr. P. Hitchcock. Calibration bar: $100 \mu \mathrm{m}$. 
Electron microscopic examination of the fiber layer confirms the impression from light microscopy that the fibers are clustered into fascicles and that the sizes of the fascicles increase toward the disk. Figure 2 shows three tracings of electron microscopic photomosaics from peripheral, intermediate, and central retina. In all cases, the sections were cut normally to the long axes of the fascicles. The fiber layer thickens near the disk, as the fascicles enlarge and lie closer together. The number of fibers per $100 \mu \mathrm{m}$ of inner limiting membrane increases from 223 to 1115 to 3805 at successively more central positions in this example. This increase results from the geometric convergence of fibers onto the optic disk and from the addition of fibers contributed by more central ganglion cells. The mean number of fibers per fascicle increases from 16 to 148 in the outer two sections and becomes indefinable close to the disk where all of the fascicles merge. This increase results from the same two tendencies and from the merger of fascicles seen in Figure 1. Some of the fascicles contain both myelinated and nonmyelinated fibers, about which more will be said below.

Figure 3 shows transverse sections through the fiber layer at about the same eccentricity as the tracing in Figure $2 b$. The vitreal surface of the retina is covered by an extraretinal cell vitreal to the basal lamina. Just deep to the basal lamina is a glial end foot, the Müller cell process that defines the retinal glia limitans. These processes are identified by their electrondense cytoplasm, which contains smooth endoplasmic reticulum, free ribosomes, and large, pale mitochondria (see also Fig. $6 d)$. We saw no specialized contacts, such as desmosomes, between adjacent end feet. The extraretinal cells, the basal lamina, and the glia limitans form the light microscopically defined inner limiting membrane. The optic fibers are clustered to the left of the columnar portion of the Müller cell and are bounded on the left by more Müller cell processes (not shown) and below by the ganglion cell somata and the inner plexiform layer (not shown).

There are two kinds of fibers, which we designate myelinated and nonmyelinated, after Wolburg (1980). The myelinated fibers are shown at high magnification in Figure $3 b$. They are wrapped by one to several cellular processes, which we assume to be glial, but neither we nor Wolburg have identified their cellular origin. This loose wrapping is restricted to the intraretinal portion of the optic fibers and is different from the conventional compact myelin of the sort found in the optic nerve (Easter et al., 1981). The myelinated fibers are systematically larger than the nonmyelinated ones and contain abundant microtubules, intermediate filaments, and infrequent mitochondria. The intermediate filaments differ from the typical descriptions of neurofilaments in the vertebrate nervous system (see "Discussion"), as they are tightly packed together and the wispy material that interconnects them is much less conspicuous.

The nonmyelinated fibers are seen more highly magnified in Figure 4. They lie superficially in the fiber layer (see also Fig. 2). Their identity as optic fibers was established by labeling them with HRP retrogradely, through the cut optic nerve (not shown). The glial processes are less intrusive in the cluster of nonmyelinated fibers than among the myelinated ones. Ignore for the moment the profiles labeled $g c$ and asterisk; these will be described below. Immediately beneath those profiles, most of the nonmyelinated fibers are quite small (diameters typically $0.1 \mu \mathrm{m}$ ) and contain microtubules but no intermediate filaments. More deeply, the axonal diameters and the number of filaments increase. The filaments are clustered, as in the myelinated fibers. Since axonal enlargement and the acquisition of intermediate filaments have been shown elsewhere to occur with maturation (Peters and Vaughn, 1967), the observations above suggest that the superficial axons are younger than the deeper ones.
In many cases, the most superficial element in the cluster of nonmyelinated fibers if clearly different from both the myelinated and nonmyelinated fibers and the glial end feet. Figure 4 shows one example of what we believe to be the growth cone of a young ganglion cell. It is quite electron-lucent and contains microtubules oriented in the direction of the fiber fascicles and very little else, apart from some smooth endoplasmic reticulum and fine, electron-dense fuzz. Superficially, it is apposed directly to the basal lamina; the glia limitans, which is usually sealed, is open. Laterally, it is apposed to the glial end feet. Deeply, it contacts both small and large nonmyelinated fibers; the latter (asterisks) are intermediate in cross-sectional area between the growth cone and the deeper nonmyelinated fibers, but they are similar to the smallest nonmyelinated fibers in that they contain microtubules but no intermediate filaments. We have never seen any large extracellular spaces anywhere in the fiber layer, including the most superficial level where the growth cones penetrate.

We believe that this putative growth cone is neuronal because its ultrastructural characteristics are very different from the nearby Müller cell processes and because we have observed similar structures in the optic nerve, as in Figure 5 . The growth cone is ultrastructurally identical to its counterpart in the retina. It is broad, electron-lucent, and contacts the basal lamina superficially, larger microtubule-containing axons deeply, and glial end feet laterally. In this case, the glia are astrocytes, recognizable by their dense clusters of cytoplasmic filaments. As in the retina, the nonmyelinated fibers that contain intermediate filaments lie deep to the ones that contain only microtubules.

Quasiserial sections of several of these putative growth cones within the retina have been made, and all have a similar shape. Figure 6 shows four sections of one of them, which was reconstructed as shown in Figure 7 . Figure $6 a$ shows a section very near the advancing tip. The growth cone, indicated by the solid arrowhead, contacts the basal lamina over about $1 \mu \mathrm{m}$, is flanked on either side by glial end feet, and lies just superficial to large microtubule-containing axons, one of which is indicated by the asterisk. At this level the growth cone contains finely filamentous material but no other cytoskeletal elements. Closer to the cell body (Fig. $6 b$ ), its appearance is more like the profile in Figure 4. Here it contacts the basal lamina quite broadly, over about $4 \mu \mathrm{m}$, and contains smooth endoplasmic reticulum and microtubules. It still maintains contact with the big tubular process below, and it extends a shallow keel down into the nonmyelinated fibers. This feature, commonly present, is also evident in Figure 4. Still closer to the soma (Fig. 6c), the process has become round and looks like the axon labeled with an asterisk, although it still touches the basal lamina. It contains microtubules but no smooth endoplasmic reticulum. The asteris $k$-labeled axon has receded and lost contact with it. Finally, in Figure $6 d$, it has lost contact with the basal lamina and resembles the larger axons which lay deep to the growth cone in $a$ and $b$.

We interpret these observations as follows. The nonmyelinated fibers are the new ones, from peripheral retina. They are superficial to the myelinated ones because each new growth cone courses along the most vitreal portion of the optic fiber layer and thereby thickens it. The fibers that had grown through slightly earlier have presumably remained in place but now lie deeper in the enlarged fiber layer. The profiles labeled with asterisks in Figures 4, 5, and 6 are examples of these. The fibers now in the most superficial position will, in time, be overlain by a new generation. Later, the fibers become myelinated, the deeper ones first. This interpretation is strengthened by several more observations to be described now.

In very peripheral retina, near the germinal zone, where only new fibers ought to be found, only nonmyelinated fibers are 

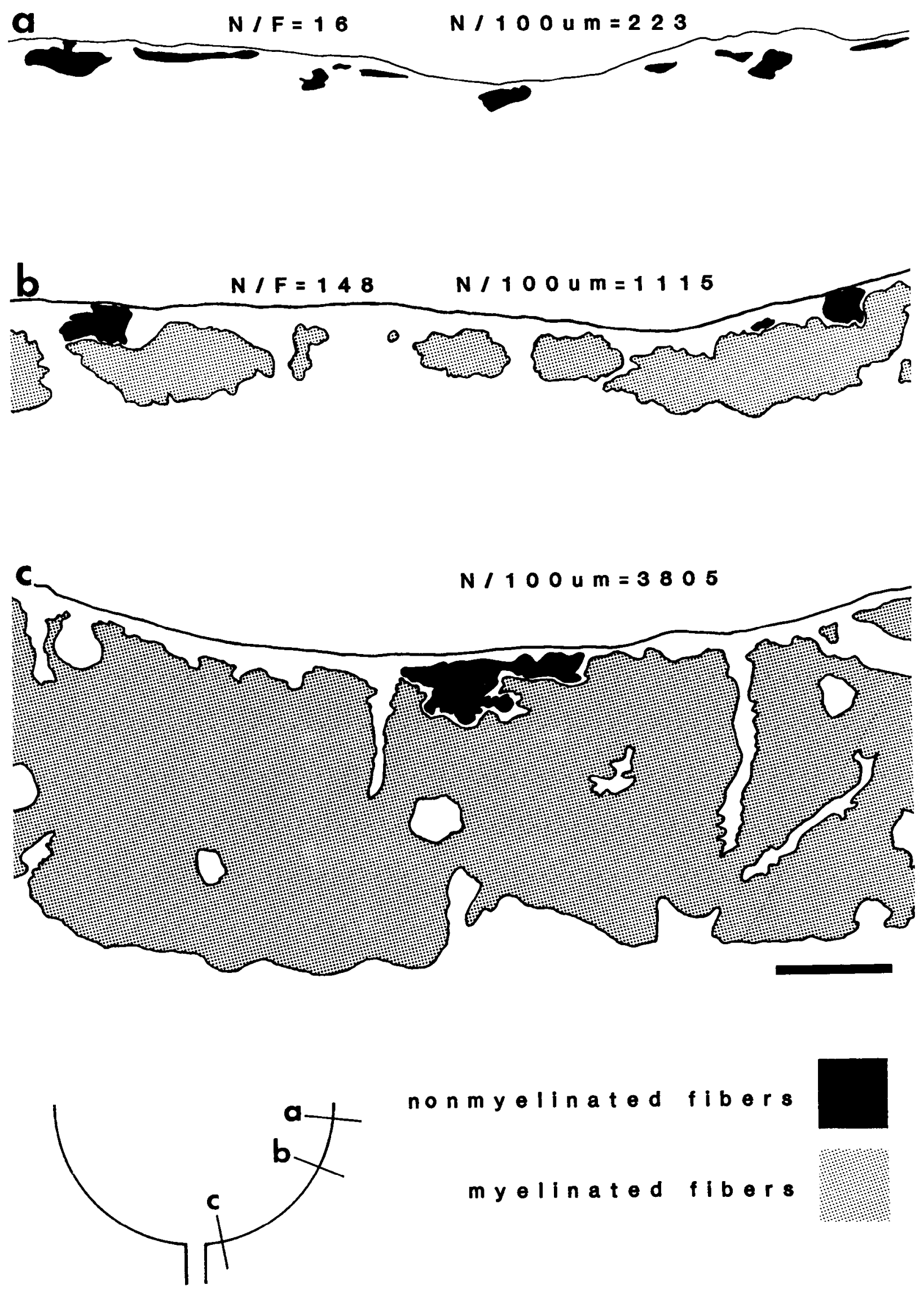

non $m$ yelinated fibers

$m y e l i n a t e d$ fibers

Figure 2. Tracings of electron microscopic photomosaics of radial sections through the retinal fiber layer at three levels (see sketch, lower left). Fibers, both nonmyelinated and myelinated, were outlined and coded (see lower right). $N / F$, mean number of fibers per fascicle; $N / 100 \mu m$, number of fibers per $100 \mu \mathrm{m}$ of inner limiting membrane. Calibration bar: $10 \mu \mathrm{m}$. 

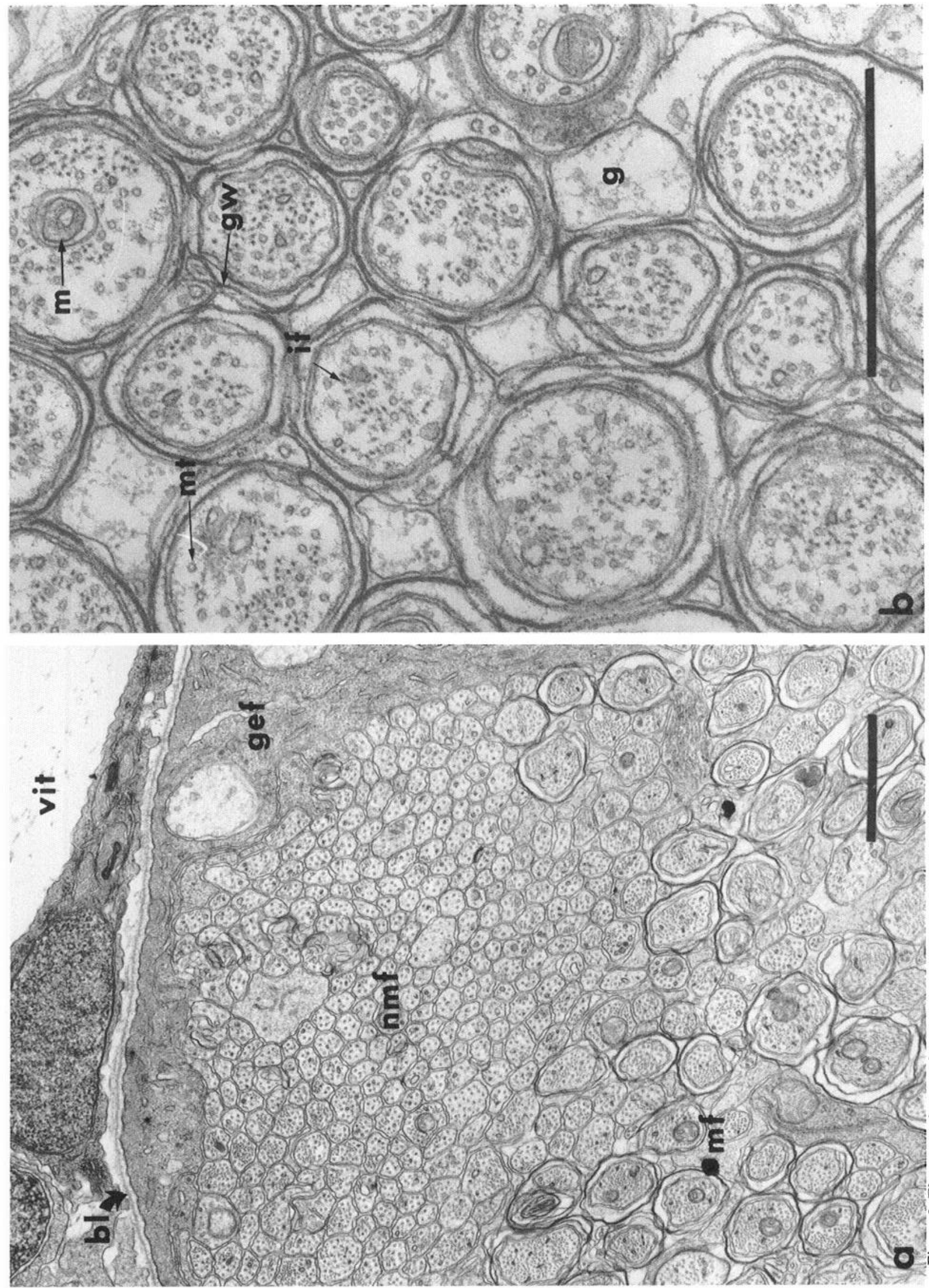

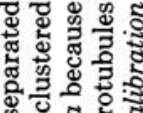
(1). ต हाँ 里 50 曲要

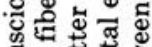
政 ฐ.

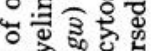

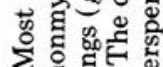
of o

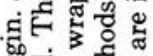

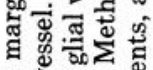
สี ซี ซี 용응 的.

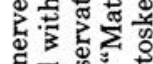

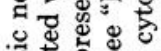
要. 응 \& 正密

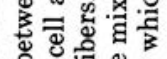

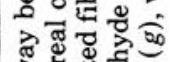
3.

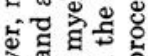
बึ.

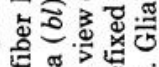
ब. 可 : : : :

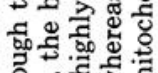
देक्ष क

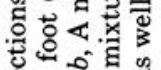
कृ 造 छह के क्षै क क

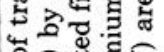

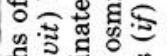
क : 究

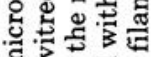
원

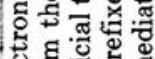
뚠 연 事

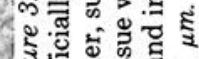

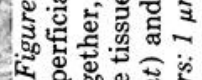

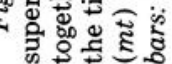




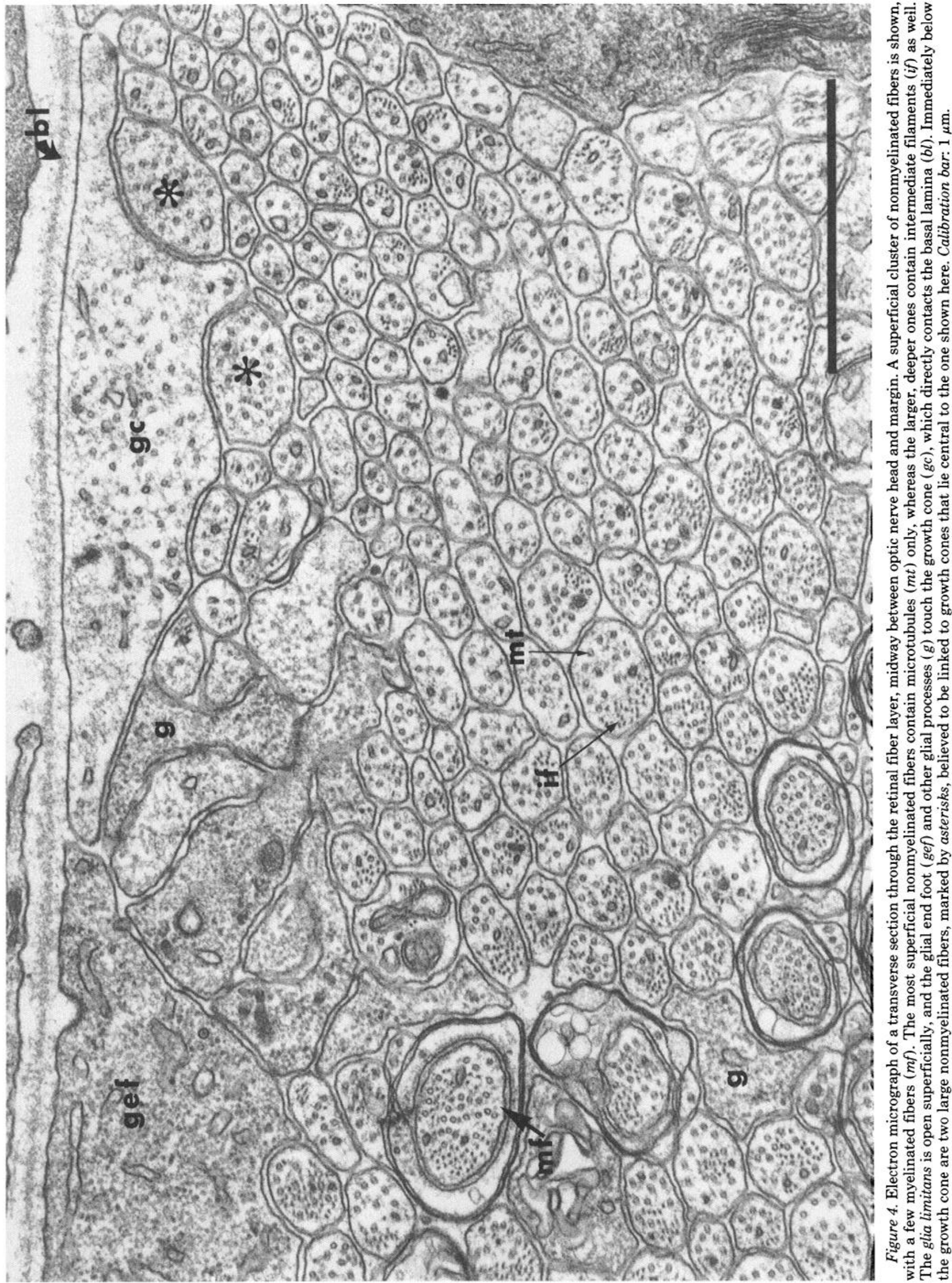




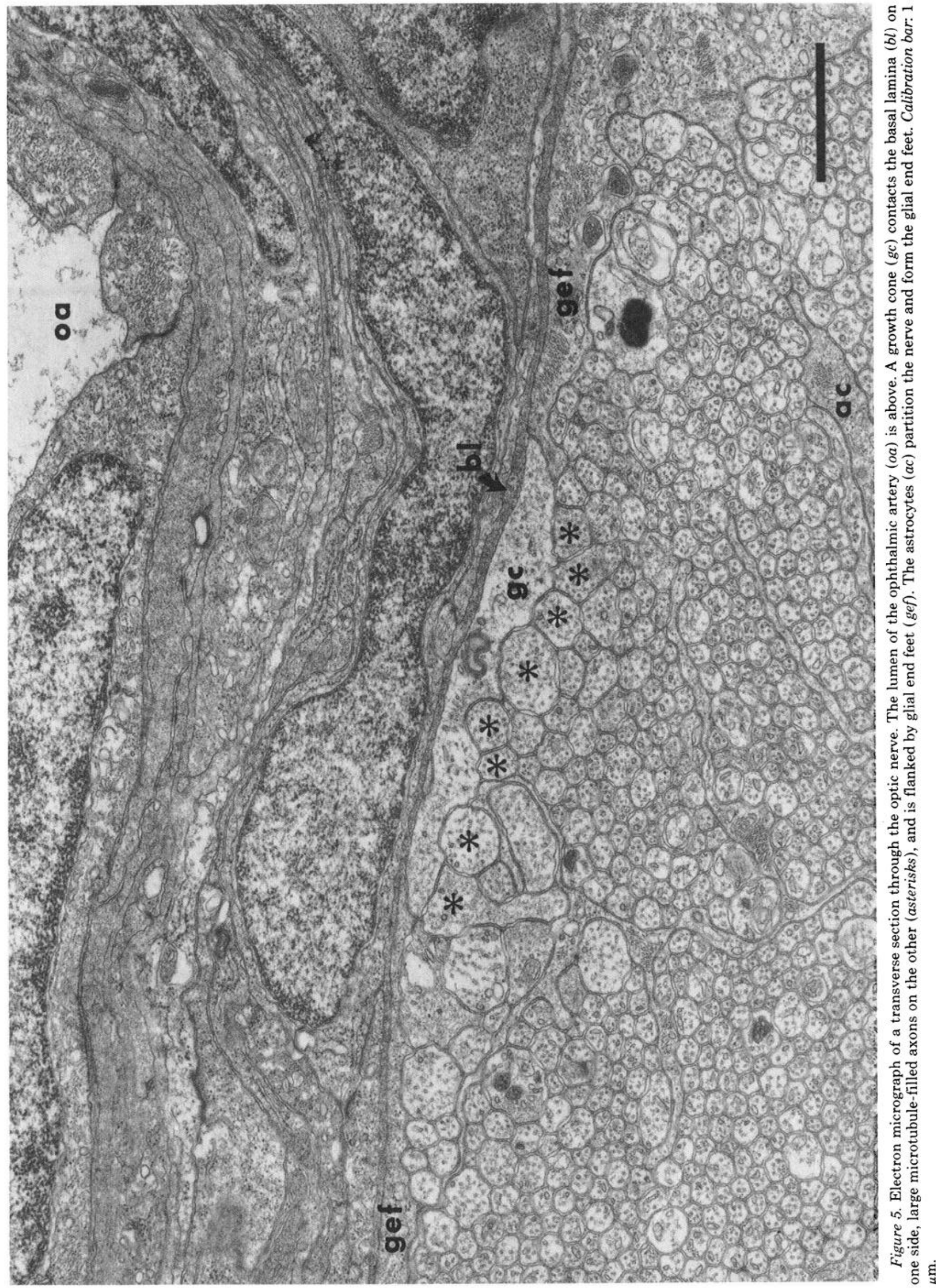



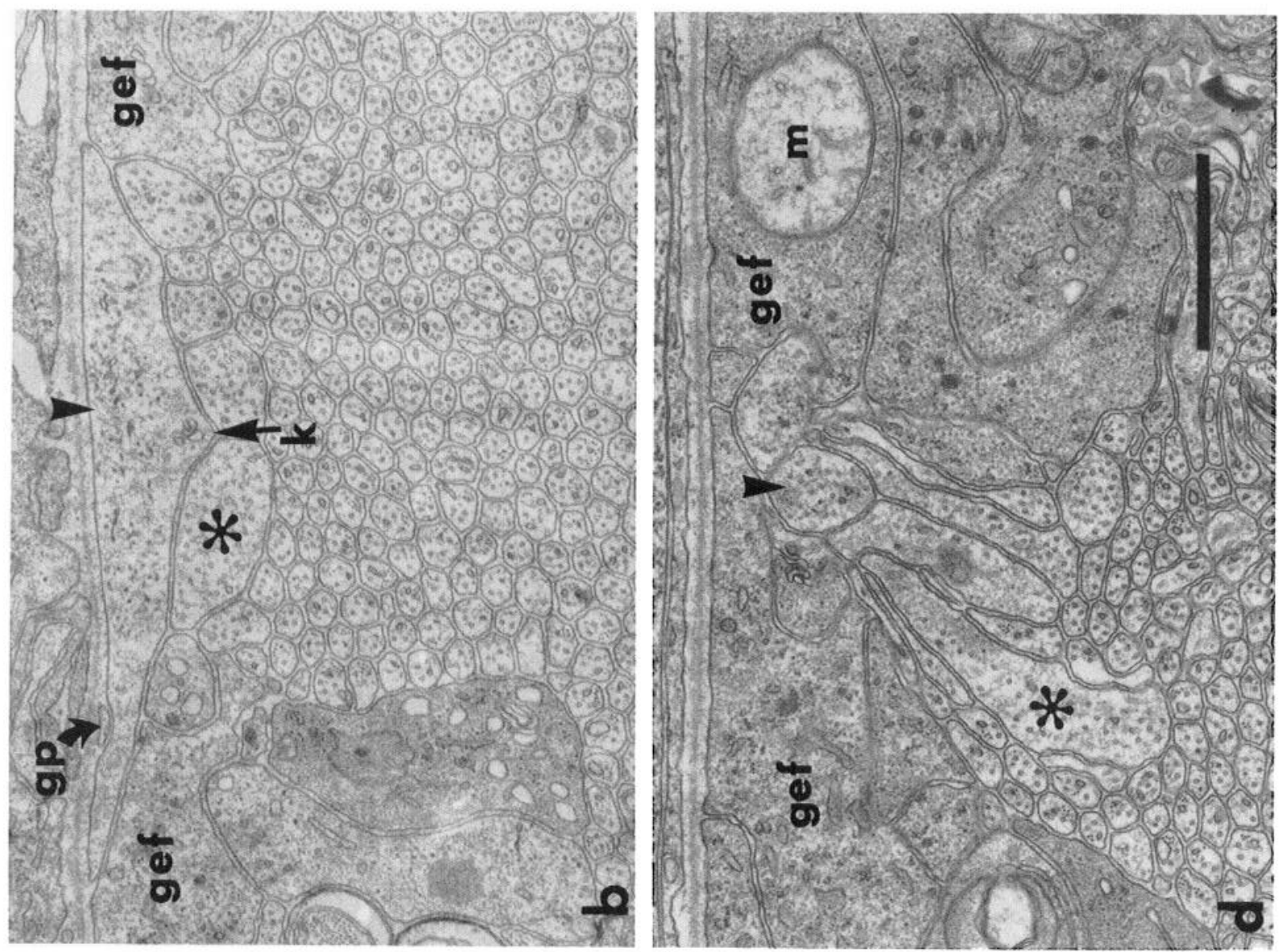

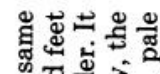

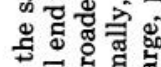

类

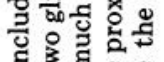

完.

ํㅜㅇ.

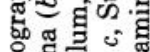

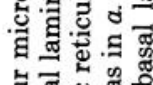

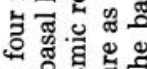

\&

4 o

进

สㄷㅇㅇ흉.

范

.

현형

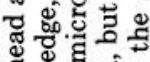

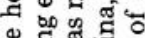

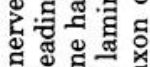

요요

응 ज्ञ

षँ

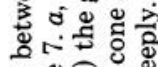

วิ

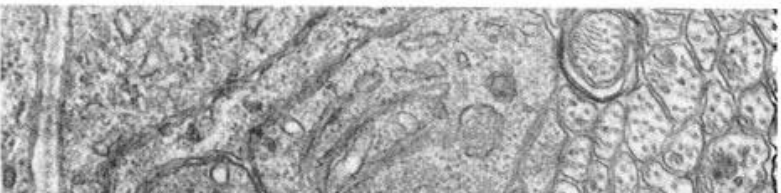
$82000 \% 5$

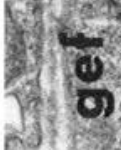

\section{Q.}

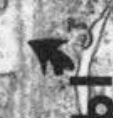

101003

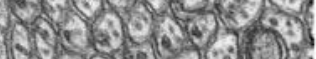

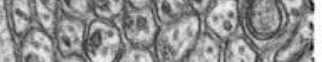
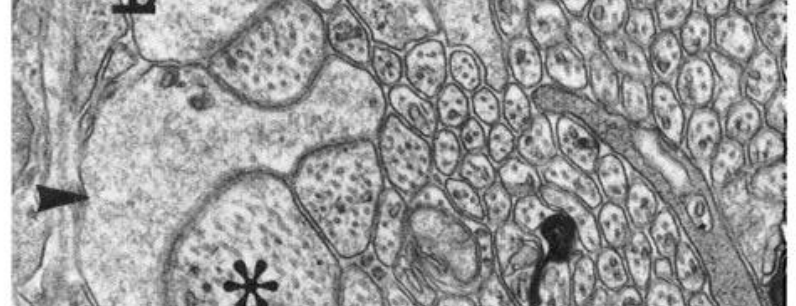

4 (น

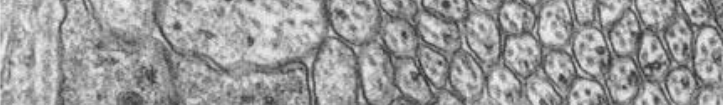

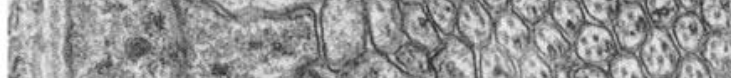

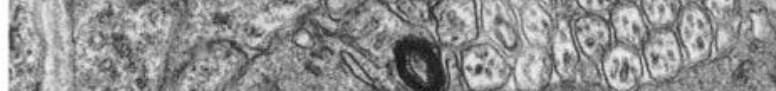

\section{2: \\ $6.8 \%$}

Sis:

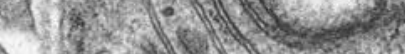

(2)

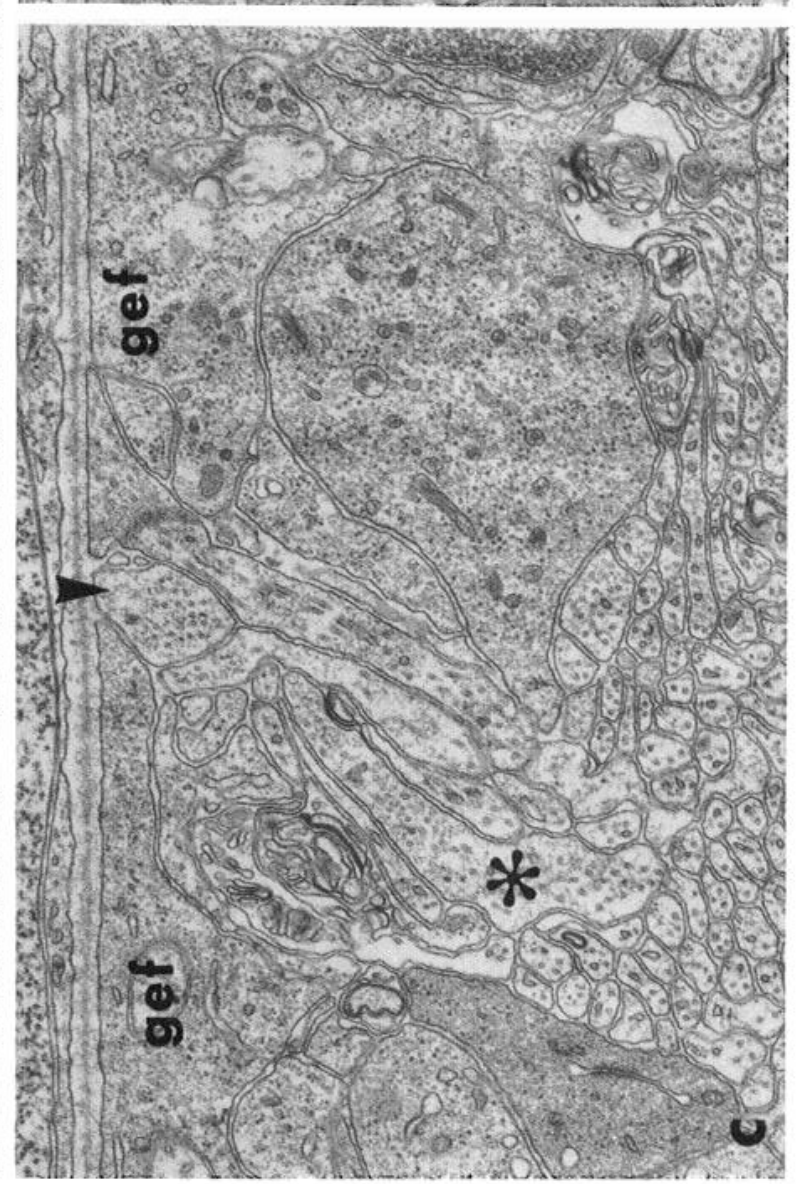

है응

.

कृ

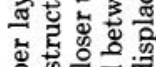

을 응 훙

๘ึ

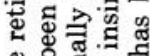

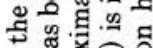

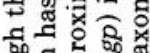

b.등 0

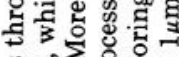

की

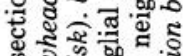

क

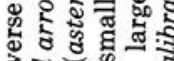

क.

政

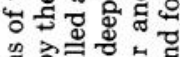

오을현

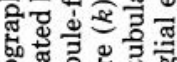

원를

范

ธ 口

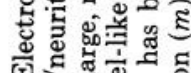

조ㅇㅝㅝ

6 훙

5้ 0 .

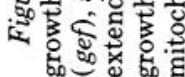



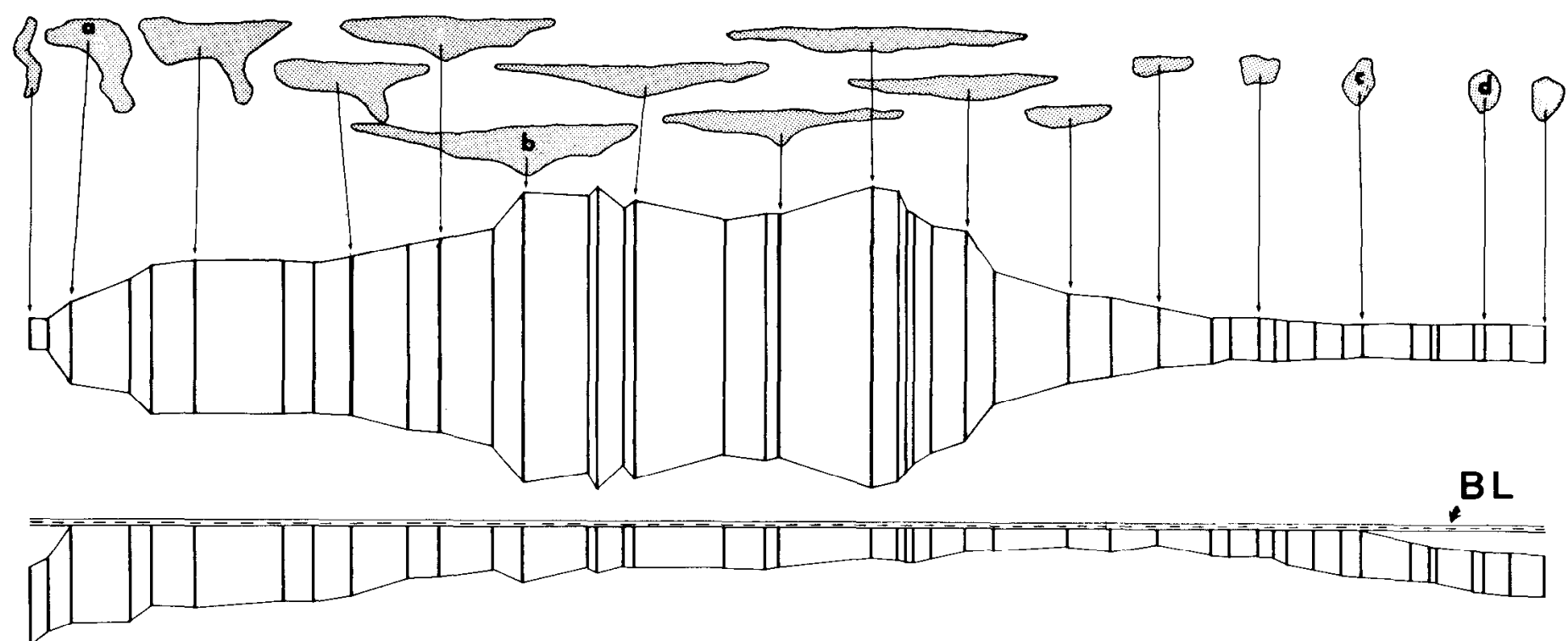

\section{MOPTIC DISK}

\section{RETINAL MARGIN}

Figure 7. A reconstruction, from 45 quasiserial electron micrographs, of a retinal growth cone. The hatched contours above show the shapes of the process in cross-section. Those labeled $a, b, c$, and $d$ were shown in Figure 6 . The middle sketch shows the process as viewed from the vitreous. Each vertical line is scaled to show the maximum width of the process. For purposes of reconstruction, the centers of successive processes were lined up. The lower figure shows this same process, viewed from the side in relation to the basal lamina (bl). Each vertical line is scaled to show the maximum depth of the process. The calibration bar applies to all three parts of the figure.

present. Figure $8 a$ shows peripheral retina (compare to Fig. 2, $a$ and $b$ ). The distance from the basal lamina to the ganglion cell soma is only about a micrometer, and this space contains very few axons. Peripheral axons (from different fields) are shown at higher magnification in Figure $8, b$ and $c$. The glial end foot separates a bundle of flattened axons from the basal lamina. Glial processes, recognized by their dark, granular cytoplasm, fill up some of the extracellular space but do not wrap around individual fibers. Unlike many of the nonmyelinated fibers in more central retina, all of the ones in this field contain both intermediate filaments and microtubules. By virtue of their position near the margin, these fibers are surely the new ones. The presence of intermediate filaments close to the cell body, and their absence more distally, may indicate that they grow from the soma more slowly than the growth cone. Whatever the reason for the cytoskeletal differences, the absence of myelinated fibers from peripheral retina supports the conclusion that the nonmyelinated fibers are the new ones.

A second line of evidence comes from the degeneration experiment. When the optic fibers are severed near the retinal margin, the axons of the peripheral cells are interrupted but those central to the cut are spared. The pattern of degeneration near the disk is shown in Figure 9. Although the preservation is poorer than in unlesioned eyes, it is adequate to show that the degenerating debris is on the vitreal side of the fiber layer (enclosed by the dashed line in Fig. 9a). Deeper fibers are intact. This supports the idea that peripheral ganglion cells send their axons superficially in the fiber layer.

Finally, we have traced the course of the nonmyelinated fibers in light and electron micrographs to the disk and into the nerve and found that they are continuous with the fascicle of nonmyelinated fibers in the nerve. We have previously shown that that fascicle originates from peripheral retinal ganglion cells (Easter et al., 1981). Electron microscopic examination of sections perpendicular to the retinal surface, through the central ophthalmic artery, shows that the superficial fibers turn into the optic nerve most centrally, adjacent to the artery, and progressively deeper fibers turn at more peripheral locations. These same sections also confirm that the basal lamina of the inner limiting membrane is continuous with the basal lamina that surrounds the central ophthalmic artery on the inner surface of the nerve. The centrally located nonmyelinated fibers were then traced in serial sections cut parallel to the retinal surface, perpendicular to the nerve. Figures 10 and 11 document their continuity with the nonmyelinated fibers in the nerve.

The series of light micrographs in Figure 10 that begins (Fig. $10 a)$ near the retinal inner limiting membrane and ends (Fig. $10 f$ ) outside the eye illustrates two features. First, it shows the shift of the artery from its central position on the retinal surface to the outside of the nerve (Bunt, 1982). Second, it shows the relations of the nonmyelinated fibers to the artery. In the retina, they encircle it (Fig. 10a) and remain in this configuration even where the artery becomes eccentric (Fig. 10, $b$ and c). Where the artery exits the nerve, the ring is broken, and the nonmyelinated fibers are arrayed in an open arc (Fig. 10d). More distal to the retina, the arc becomes more compact (Fig. $10 e$ ), and, where the nerve enters the orbit, the nonmyelinated fibers separate into the beginnings of several fascicles (Fig. $10 \mathrm{f}$ ). This was the closest position to the retina considered in the earlier study (see Fig. 2, $a$ and $b$ in Easter et al., 1981).

Electron microscopic evidence that the pale, periarterial fascicle is made up of nonmyelinated fibers is given in Figure 11, $a$ and $b$. Figure $11 a$ shows a cross-section through the nerve, at about the same level as Figure $10 a$. The lumen of the central ophthalmic artery is surrounded by several cellular layers. The basal lamina is thrown into complicated folds and is underlain by astrocytic processes. The electron density of these processes varies, but they can be identified as astrocytic because they contain numerous bundles of tightly packed intermediate filaments. Junctional complexes join some adjacent processes (see also Lanners and Grafstein, 1980), but not where growth cones abut directly against the basal lamina (Fig. 5; Scholes, 1981). Just inside the astrocytic processes are the fascicles of nonmyelinated fibers, and farther from the ophthalmic artery are 

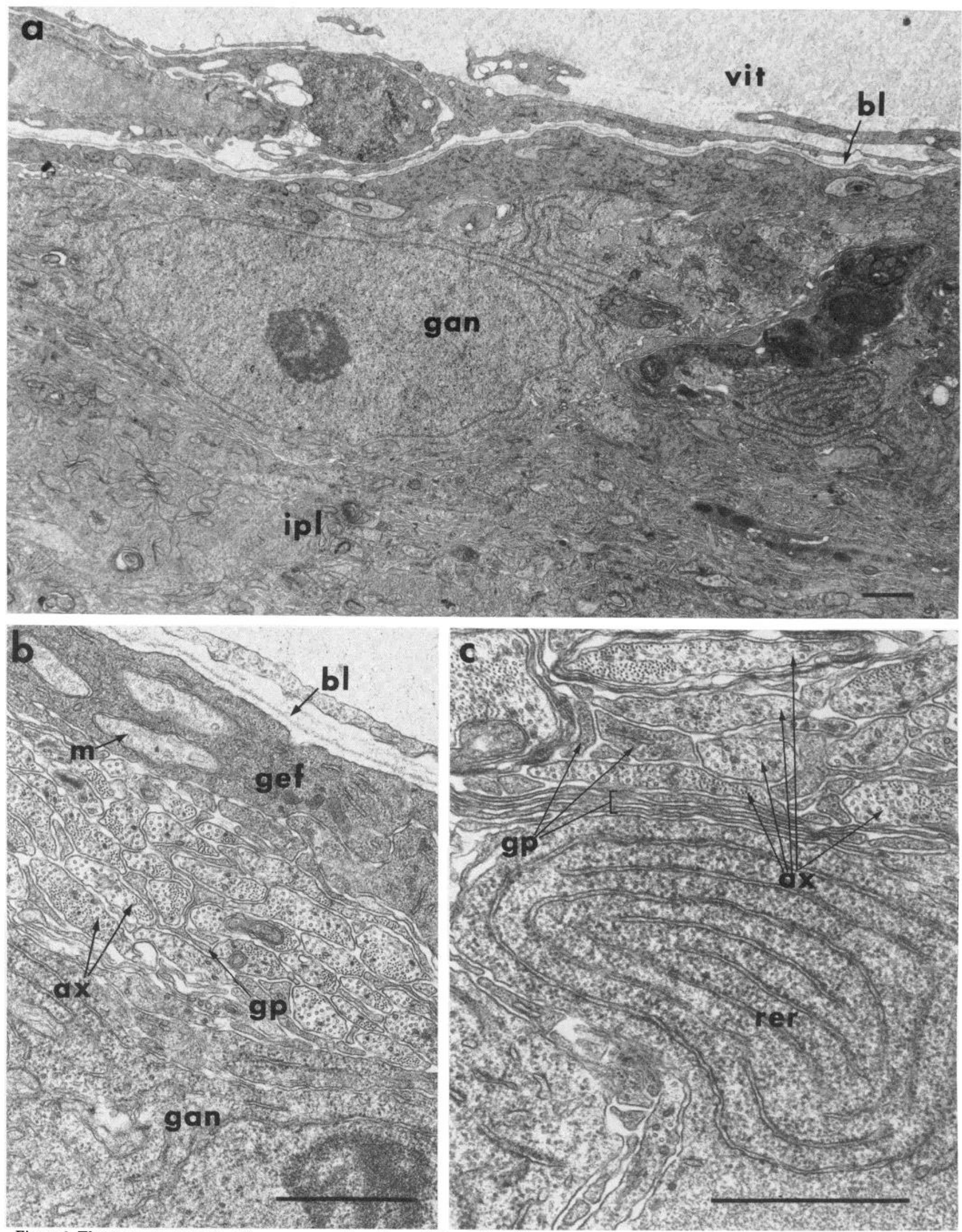

Figure 8. Electron micrographs of transverse sections through the retinal fiber layer, very near the retinal margin. $a$, The ganglion cell ( $g a n$ ) is recognized by its position, large nucleus, and nucleolus. The developing inner plexiform layer (ipl) is deep to it, and a very thin optic fiber layer, glial end feet, basal lamina $(b l)$, and the vitreous (vit) lie superficially. $b$, A more highly magnified view of another ganglion cell, axons $(a x)$, and glial processes $(g p)$ in the fiber layer. The glial end foot ( $g e f$ ), with its characteristic pale mitochrondria $(m)$ lies superficially, just beneath the basal lamina $(b l) . c$, A slightly more highly magnified view of the perikaryon of a ganglion cell with its extensive and orderly rough endoplasmic reticulum (rer). Axons ( $a x)$ are flattened; they are recognized by their pale cytoplasm and cytoskeletal elements cut orthogonal to their long axes. Glial processes $(g p)$ are darker and lack microtubules. Calibration bars: $1 \mu \mathrm{m}$. 

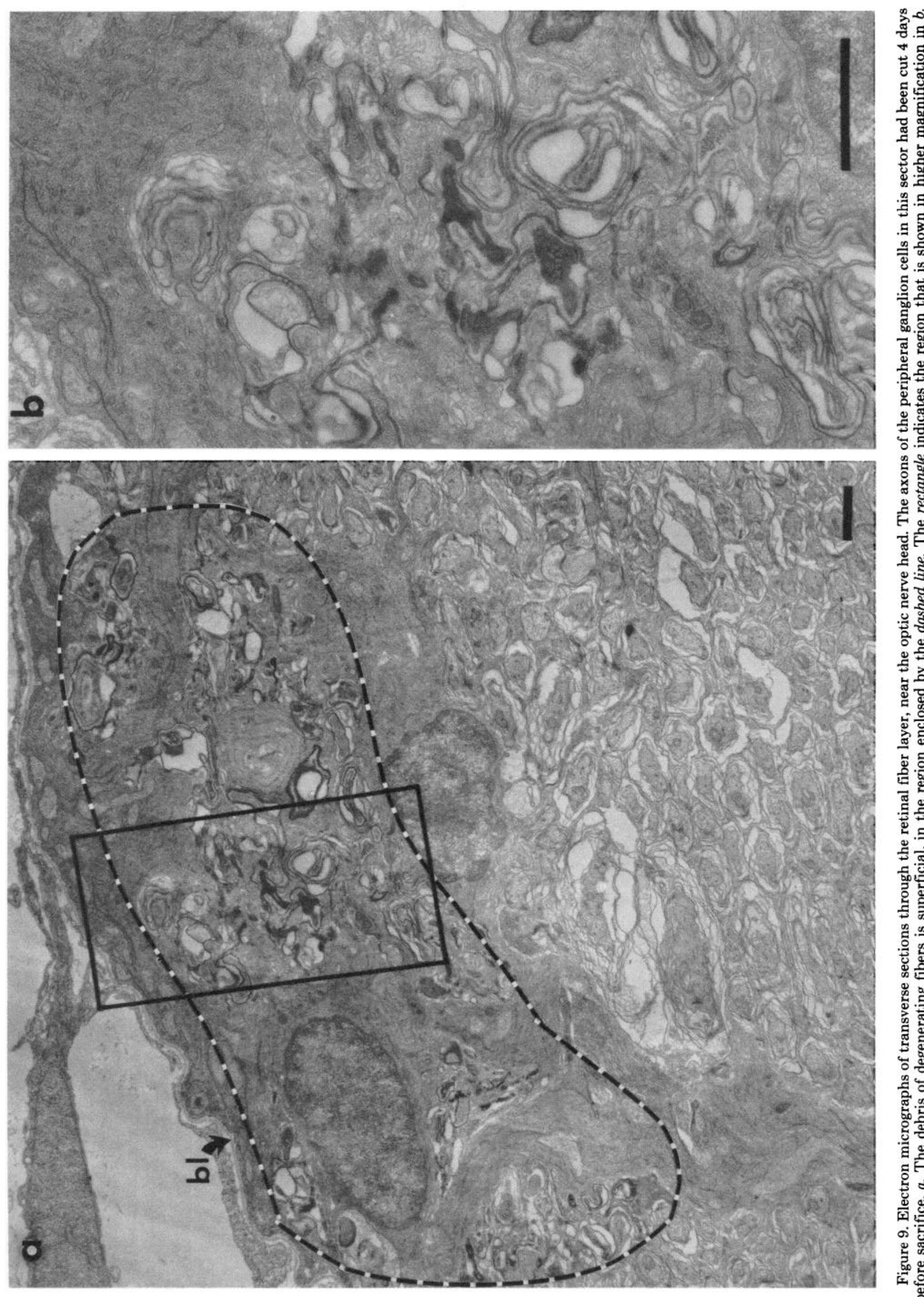

음

สิ

幽

हुं

ธ

एँ

ฐ

흠

용

紊京

范

농뭉

过. ํㅜㄴ

ฮี

.

ฐँ

말ㄹㄹ

일

o.

递

总.

क्ष

站要

o

承.

웡

范

of

的

可造

के

边

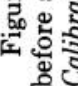



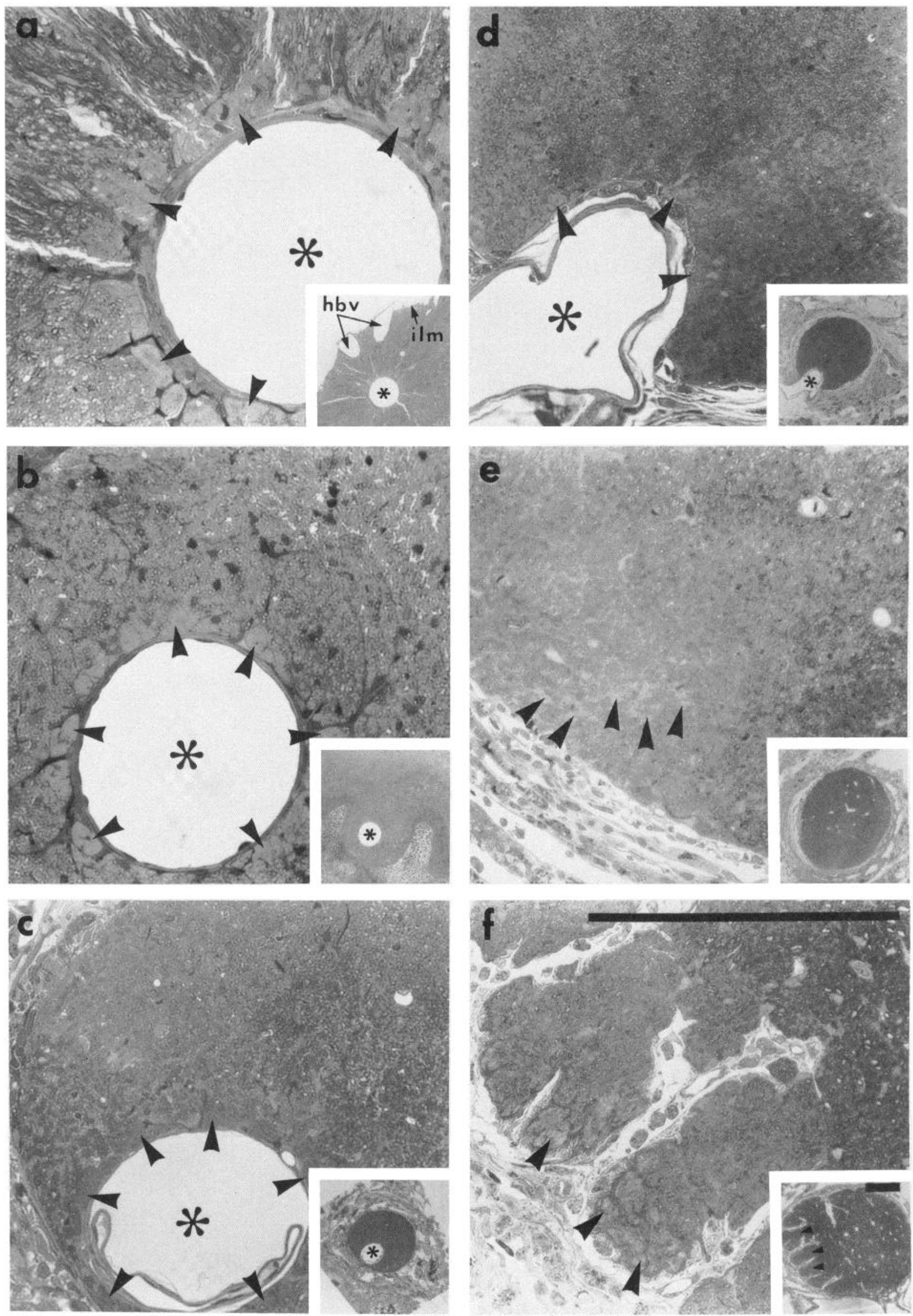

Figure 10. Light micrographs of successive sections through the optic nerve head and optic nerve. The larger micrograph in each panel is a detail of its inset, both of which are oriented so that the ventral direction is at 8 o'clock. The ophthalmic artery is indicated by an asterisk. The arrowheads show the lightly stained nonmyelinated fibers (see Fig. 11). $a$, The most superficial section, through the retinal fiber layer and cutting the inner limiting membrane (ilm) and hyaloid blood vessels $(h b v)$. $b$, Slightly deeper section, passing through the plane of the photoreceptors' outer segments and the neural retina. $c$ to $f$, Successively deeper sections through the sclera and ending outside the eye. The inset in $f$ shows the beginnings of the fascicles (arrowheads) that subdivide the nonmyelinated fibers. Calibration bars: $100 \mu \mathrm{m}$. 



Figure 11. Electron micrographs of transverse sections of the intraretinal optic nerve. $a$, The ophthalmic artery (oa) and an adjacent portion of the nerve. The basal lamina $(b l)$, which is continuous with that of the retinal inner limiting membrane, is underlain by dark astrocytic processes and bundles of nonmyelinated fibers $(\mathrm{nmf})$. More peripherally (i.e., farther from the artery) there are myelinated fibers $(\mathrm{mf})$. The nerve is partitioned by astrocytic processes $(a c) . b$, A detail of nonmyelinated fibers (nmf) near the artery, bounded by astrocytic cytoplasm $(a c)$. $c$, A detail of the periphery of the nerve showing the peripheral basal lamina $(b l)$, astrocytic wrapping $(a c)$, and abundant myelinated and unmyelinated fibers. Calibration bars: $1 \mu \mathrm{m}$. 


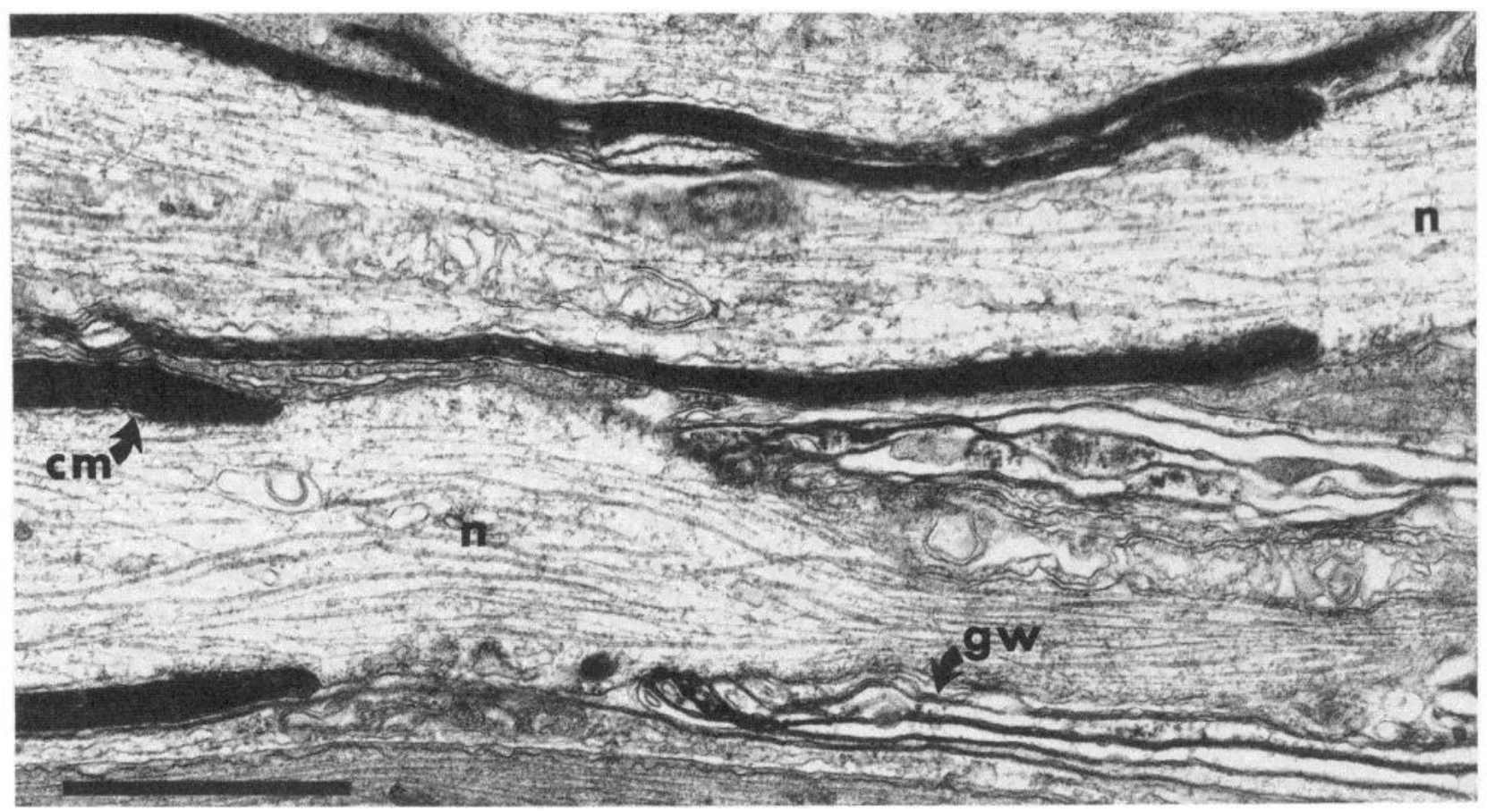

Figure 12. Electron micrograph of a tangential section of the retinal fiber layer, near the optic disk. The disk lay to the left, and the retinal margin to the right. Two nodes $(n)$ are shown. The lower one has compact myelin $(\mathrm{cm})$, typical of fibers in the optic nerve, to the left of the node and loose glial wrappings ( $g w$ ) to the right. Calibration bar: $1 \mu \mathrm{m}$.

the myelinated fibers. Figures 5 and $11 b$ show the nonmyelinated fibers and the cytoplasm of the astrocytes at higher magnification. In summary, the nonmyelinated fibers close to the artery in the optic nerve head are continuous with the superficial ones in the retina and with those in the nerve.

One final point is that the state of myelination of individual fibers varied along their length. Figure $11 c$ shows a field in which many of the fibers are surrounded by compact myelin, but many others are unwrapped. We infer from the abundance of these nonmyelinated profiles that many of the fibers that are myelinated in the retinal fiber layer are nonmyelinated over the intraretinal portion of the nerve and are myelinated outside the eye. In other cases, there is no unwrapped portion, as the wrapping changes from the loose to the compact variety across a single node, as in Figure 12.

\section{Discussion}

Recapitulation. We suggest that the cell proliferation at the retinal margin produces ganglion cells whose axons grow out in the most superficial level of the retinal fiber layer. The enlarged axonal tips, the growth cones, join fascicles that contain other, recently produced nonmyelinated fibers, while maintaining direct contact with the basal lamina of the inner limiting membrane. This most superficial position is maintained into the nerve. The trailing process of each growth cone is initially thicker than the other nonmyelinated fibers among which it is nestled, but in time it thins down to a diameter of a few tenths of a micrometer or less and maintains its superficial position in the fiber layer, albeit separated from the basal lamina by the glial end feet, which seal up the glial limitans just behind the advancing growth cone. Initially, this tiny new axon has only microtubules, but over time it enlarges, acquires intermediate filaments, and eventually is wrapped by glial processes. Concurrent with this development, the axon loses its superficial position as new fibers grow in above it. This very orderly age-related growth produces a stratified fiber layer, as sketched in Figure 13.

\section{Optic Fiber Lamination}

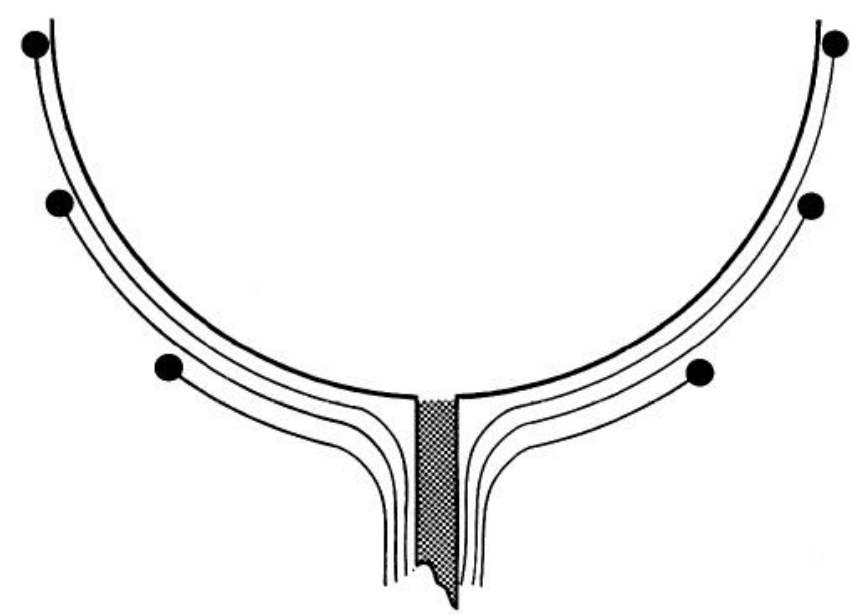

Figure 13. Sketch of the lamination in the retinal fiber layer and the adjacent optic nerve. The most peripheral cells project their axons in the most superficial layer of the retina, and they occupy the most central portion of the optic nerve, adjacent to the ophthalmic artery (stippled). Axons from successively more central somata run more deeply in the retina and occupy positions closer to the outer edge of the nerve.

This interpretation depends heavily on the conclusion that the nonmyelinated fibers are the new ones. This was based on the following arguments. First, the ultrastructure of the fibers changes in a regular way, from superficial to deep, which is consistent with their increasing age: they enlarge, add filaments, and become myelinated. Moreover, growth cones are always superficial to all of the nonmyelinated fibers. Second, since myelination always follows fiber outgrowth, there must be a population of transiently nonmyelinated fibers in both the 
retina and the optic nerve, because the number of myelinated fibers increases with age (Easter et al., 1981). Third, the nonmyelinated fibers in the retina are continuous with the fascicles of nonmyelinated fibers in the nerve, which were previously shown to be the new ones. Fourth, the nonmyelinated fibers are the only ones present in peripheral retina, consistent with the idea that they originate from peripheral (new) ganglion cells. Fifth, the degenerating axons of peripheral ganglion cells are only found in the superficial part of the optic fiber layer.

Cytoskeleton. The intermediate filaments in the optic fibers are more tightly packed than the neurofilaments described in central and peripheral neurons of other vertebrates (Fawcett, 1981). In addition, the wispy material that connects the individual filaments together is much less conspicuous. These ultrastructural differences have an interesting biochemical correlate. Mammalian neurofilaments consist of a triplet of peptides (approximate molecular weights: $70,000,150,000$, and 200,000 daltons; for references, see Tapscott et al., 1981), the largest of which probably corresponds to the wispy material seen electron microscopically (Willard and Simon, 1981). According to Quitschke and Schechter $(1983,1984)$ the intermediate filaments in the optic axons of goldfish consist only of a single component, with a molecular weight of about 58,000 daltons. Thus, the absence of the high molecular weight species in these filaments correlates with their ultrastructure; they lack the prominent wispy material. (This description of the intermediate filaments in the optic axons of goldfish is disputed by McQuarrie and Lasek (1981), who reported in an abstract that these axons have a triplet of peptides, with molecular weights of $60,000,80,000$, and 135,000 daltons.) It is interesting that the neurofilaments in the trochlear nerve of goldfish (Scherer and Easter, 1984) appear ultrastructurally similar to those in mammals. However, no biochemical information is available for this nerve.

Myelination. Myelinated fibers in the retina of cyprinids have been described by two earlier workers. Witkovsky (1971) noted that the retinopetal fibers that synapse in the inner plexiform layer are myelinated. Wolburg (1980) confirmed the existence of intraretinal myelinated fibers but showed that most are only lightly and loosely myelinated, and these are much too numerous to be attributed to retinopetal fibers. He concluded that they must be, for the most part, retinofugal, and we concur. However, we are somewhat uneasy with calling these fibers "myelinated" since the "myelin" clearly differs structurally from the conventional sort; there may be biochemical and antigenic differences as well.

Growth cones. The identification of the growth cone is an important element in our study. Although this structure has been known to light microscopists since the time of Ramón y Cajal (1890, cited by Silver and Sidman, 1980), its ultrastructural characteristics are controversial. In culture, growth cones can be unambiguously identified as the growing neuritic tips, which consist of flattened enlargements from which numerous processes extend. The enlargement usually contains smooth endoplasmic reticulum, clear and dense-cored vesicles, mitochondria, and an occasional group of neurofilaments or microtubules. The extensions, which are either long and fine (called microspikes or filopodia) or broad and thin (called veils or lamellipodia), consist exclusively of fine, filamentous material (Yamada et al., 1971; Bunge, 1973; Letourneau, 1979) which is probably actin (Letourneau, 1981). The axonal growth cones in regenerating peripheral nerves are ultrastructurally similar to those in vitro (Wettstein and Sotelo, 1963; Morris et al., 1972; Scherer and Easter, 1984), except that extensions containing fine, filamentous material seem to be much rarer.

The ultrastructure of axonal growth cones has been described in a number of different places in the developing nervous system of vertebrates. Those in the dorsal horn of rabbits
(Tennyson, 1970), the optic nerve of cichlid fish (Scholes, 1981), the retina of chicks (Krayanek and Goldberg, 1981), and the longitudinal fiber tracts in the spinal cord of Xenopus (Nordlander and Singer, 1982b) are similar to the ones in our material. The enlargements contain smooth endoplasmic reticulum and finely filamentous material, as well as a variable number of mitochondria and microtubules; the extensions, when present, exclusively contain finely filamentous material. However, other putative growth cones seem to be smaller and simpler and to consist mostly of membranous material (Del Cerro and Snider, 1968; Rakic and Riley, 1983). Although they may be growth cones, we do not feel confident in using only those structural criteria, since similar profiles have been shown to be artifacts of glutaraldehyde fixation (Hasly and Hay, 1978; Nuttall and Wessells, 1979).

The structure of the growth cones in our material is relatively simple by comparison with some that have been described (e.g., Raper et al., 1983). We have never seen microspikes, only a broad paddle-shaped dilation with a shallow ridge, or keel, below. It is conceivable that our preparative procedures destroyed more complex structures, but a more likely explanation emerges from the work on the development of the visual system in Daphnia (Flaster et al., 1982). The first axon that advances from the ommatidium toward the central nervous system has a very complex growth cone. The axons that follow later appear to climb along the path established by the first, and their growth cones are simpler. The growth cones that we have described in the retina of goldfish, and all of the examples of other growth cones in vertebrates cited above, are following well established paths; perhaps the structural complexity or the lack thereof indicates the complexity of the problem-to establish a new path or to follow an old one.

We have seen two growth cones in contact with one another within the retina only once, and in that case they touched at just one point. This may be no more than an indication of how infrequently they are produced, but the observation also suggests that their mutual fasciculation, sometimes noted in vitro (Nakai, 1960) and in vivo (Roberts and Taylor, 1983; Taylor and Roberts, 1983) is not essential for axonal pathfinding in the retina.

We found many growth cones in some retinas and few or none in others. There could be several reasons for this variability, including the season and the uncertain nutritional states of the individuals, but we have not investigated this matter.

Substrates for axonal guidance. The extremely superficial location of retinal growth cones is consistent with several other reports. In the chick retina, Rager (1980) and Krayanek and Goldberg (1981) described the growth cone in the most vitreal level of the fiber layer, although none of their pictures show it in direct apposition to the basal lamina. Hinds and Hinds (1974) made similar observations in the developing mouse retina. The developing retinal fiber layer in chicks appears much less crowded than in fish; indeed, Krayanek and Goldberg (1981) commented on the existence of abundant intercellular space to which they attributed functional significance (see also Silver and Robb, 1979; Silver and Sidman, 1980). Bodick and Levinthal (1980) examined the early development of the optic nerve in the zebrafish and saw very little extracellular space in the fiber layer. They also reported that growth cones in the retina are very superficially placed near the glia limitans (their Fig. 1e) but apparently not in contact with the basal lamina. Perhaps some of the variability in the opening of the glia limitans can be attributed to the presence or absence of junctional complexes between the glial cells and the open spaces between them. We agree with Bodick and Levinthal (1980) that open extracellular channels probably do not play a role in axonal guidance in the fish retina.

In several other instances, growth cones have been found to 
contact basal laminas. In the developing second thoracic ganglion of the grasshopper, the Q1 neuron's growth cone pioneers the formation of the posterior commissure by growing across a basal lamina (Raper et al., 1983). In the developing spinal cord of Xenopus, the growth cones of the longitudinal fiber tracts sometimes contact the basal lamina of the neural tube (Roberts and Hayes, 1974; Nordlander et al., 1981; Nordlander and Singer, 1982a, b; Taylor and Roberts, 1983). In the initial innervation of the skin of embryonic Xenopus, growth cones grow along the basal lamina of the epidermis (Roberts and Taylor, 1982, 1983; Taylor and Roberts, 1983). In the regenerating trochlear nerve of goldfish, the growth cones always contact the basal lamina of the Schwann cells, often extensively (Scherer and Easter, 1984).

These observations in very disparate places suggest that basal laminas might be involved in axonal outgrowth. Halfter et al. (1983) have suggested that the basal lamina of the retinal inner limiting membrane provides directional cues for axons, but their experimental procedures that resulted in randomly directed growth probably destroyed more than just the basal lamina. Scholes (1981) has suggested that growth cones deposit material on the basal lamina-a "snail's trace"-which later growth cones follow. Another plausible role for basal laminas would be as adhesive surfaces. Letourneau (1982) has proposed that growth cones sample the surfaces nearby and advance along the most adhesive one. If growth cones were particularly adherent to basal laminas, then this might explain their location. Support for this idea comes from the fact that four of the known components of basal laminas-laminin (Rogers et al., 1983), fibronectin (Akers et al., 1981; Rogers et al., 1983), type IV collagen (Vlodavsky et al., 1982), and heparan sulfate (Lander et al., 1982) - have been shown to promote neuritic outgrowth in culture. However, it must be acknowledged that the growth cones have three immediate neighbors in our material: basal lamina above, glial end feet laterally, and recently produced fibers below. Selective adhesion to any of them could account for its superficial position. The foregoing remarks indicate that we think the basal lamina warrants serious consideration, especially in view of the observation that the leading and trailing portions of the advancing neurite are not in contact with it (Fig. 7). This static image implies that the growing tip must push the glial end feet aside and take over a considerable area on the basal lamina that they had previously occupied.

Conversely, this observation also suggests that glial end feet probably do not provide a significant part of the adhesive substrate. Not only are they pushed aside, but they touch only a very small fraction of the advancing tip. Of course, they may produce the basal lamina, as do the Schwann cells in the peripheral nervous system (Bunge et al., 1982), so if the basal lamina is important, then the glia are indirectly so.

The third structure that may guide growth cones is the bundle of nonmyelinated fibers. They contact about as big a fraction of the growth cone as the basal lamina, so if area of contact is to be used as an indication of adhesion, they, too, are likely candidates. Axons and growth cones fasciculate in culture, and special cell adhesion molecules have been identified which mediate this interaction (Edelman, 1983). A very compelling case for favoring the fibers can be made with reference to Figure 2, which illustrates that the bundles of nonmyelinated fibers are not found everywhere across the fiber layer but only at certain positions, separated by many tens of micrometers. The fact that growth cones were always found on such preexisting bundles, although the basal lamina, the glial end feet, and the myelinated fibers were available everywhere else, could indicate that the most important of the three neighbors are the other fibers-specifically the new, unwrapped ones. An alternative explanation for the clustering is that all of the axons have followed and contributed to the hypothetical "snail's trace" on the basal lamina (Scholes, 1981). A final reason for favoring the axons over the basal lamina is that in lamprey, the optic fiber layer is deep in the inner plexiform layer (Walls, 1963), far removed from the inner limiting membrane, which, therefore, could not be involved in axonal guidance.

Spatially ordered pathways. We next turn to the general issue of the importance of spatial order in fiber pathways. The often cited view of Horder and his collaborators (summarized in Horder and Martin, 1978) is that mechanical guidance of axons is necessary and sufficient for the formation of an ordered projection such as the one between retina and tectum. Although our work is consistent with that view, we do not believe that it provides strong support. In this section we will compare the order that we have found with other systems examined by other investigators and attempt to arrive at an interpretation that is broadly consistent with what has been observed in developing nervous systems generally.

First, does it generally hold that the most recently formed retinal axons run most superficially in the fiber layer? This has been examined at early stages of development only in zebrafish (Bodick and Levinthal, 1980), chick (Rager, 1980; Krayanek and Goldberg, 1981), and mouse (Hinds and Hinds, 1974) and seems to be true in all cases. The retinas of these animals grow by the addition of anuli, with the consequence that axons from peripheral retina are superficial and central retinal axons are deep. The correlation of the superficial/deep position in the fiber layer with the peripheral/central position on the retina has been found in two species of macaque monkeys (Ogden, 1983a) but not in the owl monkey (Ogden, 1983b). Unfortunately, the patterns of retinal growth have not been established for any of these species, so the observations do not help to evaluate the generality of the correlation between axonal age and superficial position.

Second, is it generally found that fibers of the same age run together in the nerve? Bunt and Horder (1983) have used degeneration following retinal lesions and transport of HRP to search for retinotopia in the cross-section of the optic nerves of a few nonmammalian vertebrates. They found that it was most striking in teleosts, lizards, and birds but less so in urodeles and anurans. All of the species they studied show annular retinal growth, except the reptile, in which the pattern of retinal growth is unknown. These results suggest that the pattern in fish may well be general, but more recent work on the optic nerve of Rana pipiens causes that idea to be rejected. Scalia and Arango (1983) and Reh et al. (1983) have shown that fibers from neighboring ganglion cells in one part of the retina separate at the optic disk to enter two separate tracks in the nerve. Curiously, these two tracks unite at the chiasm and create an annular order that did not originate near the retina. In the cat (Torrealba et al., 1982), the optic nerve seems to be completely scrambled, but a complex retinotopic organization emerges in the optic tract. This emergence of order from disorder along the proximodistal axis has also been noted in the developing motor pathways of the hindlimb of the chick (Lance-Jones and Landmesser, 1981a). The motor neurons that innervate the chick's hindlimb are produced over several days, and the axons destined for any given muscle may exit the cord through one or more ventral roots. The axons destined for the same muscle are scrambled proximal to the lumbosacral plexus, but within the plexus they gather together to form coherent, muscle-specific bundles. These examples of the emergence of spatial order in pathways, as opposed to the maintenance of an order established at the origin of a projection, argue against the necessity for order as a primary determinant of the topography of a projection. Indeed, they suggest that growing nerve fibers can probably sense and react to their environment, both its non-neuronal positional landmarks and other axons (see also Lance-Jones and Landmesser, 1981b). 
Summary. The age-related order of axons in the optic nerve of the goldfish apparently originates intraretinally, as new ganglion cells send their axons in the most superficial level of the fiber layer toward the optic nerve head. There, they turn away from the vitreous and establish a nerve which, in crosssection, maintains the retinotopic order. The choice of the most superficial level is dictated by uncertain features, of which the most likely possibilities are mutually adhesive nonmyelinated axons from young ganglion cells and an adhesive busul lamina. Relatively less important are the glial end feet and preformed channels. We recognize that our observations treat a very late stage of development; the factors that are important at earlier stages remain to be established.

\section{References}

Adams, J. C. (1977) Technical considerations on the use of horseradish peroxidase. Neuroscience 2: 141-146.

Akers, R. M., D. F. Mosher, and J. E. Lilien (1981) Promotion of retinal neurite outgrowth by substratum-bound fibronectin. Dev. Biol. 86: 179-188.

Bodick, N., and C. Levinthal (1980) Growing optic nerve fibers follow neighbors during embryogenesis. Proc. Natl. Acad. Sci. U. S. A. 77: 4374-4378.

Bratton, B., S. S. Easter, Jr., C. A. O. Stuermer, and S. S. Scherer (1983) Goldfish retinal axons: Intraretinal pathways. Invest. Ophthalmol. Vis. Sci. Suppl. 24: 8.

Bunge, M. B. (1973) Fine structure of nerve fibers and growth cones of isolated sympathetic neurons in culture. J. Cell Biol. 56: 713-735.

Bunge, M. B., A. K. Williams, and P. M. Wood (1982) Neuron-Schwann cell interaction in basal lamina formation. Dev. Biol. 92: 449-460.

Bunt, S. M. (1982) Retinotopic and temporal organization of the optic nerve and tracts in the adult goldfish. J. Comp. Neurol. 206: 209226.

Bunt, S. M., and T. J. Horder (1983) Evidence for an orderly arrangement of optic axons within the optic nerves of the major nonmammalian vertebrate classes. J. Comp. Neurol. 213: 94-114.

Cook, J. E. (1982) Errant optic axons in the normal goldfish retina reach retinotopic tectal sites. Brain Res. 250: 154-158.

Del Cerro, M. P., and R. S. Snider (1968) Studies on the developing cerebellum. Ultrastructure of growth cones. J. Comp. Neurol. 133: 341-362.

Easter, S. S., Jr., A. C. Rusoff, and P. E. Kish (1981) The growth and organization of the optic nerve and tract in juvenile and adult goldfish. J. Neurosci. 1: 793-811.

Easter, S. S., Jr., B. Bratton, S. S. Scherer, and C. A. O. Stuermer (1983) New optic axons in the goldfish retina. Soc. Neurosci. Abstr. 9: 211 .

Edelman, G. M. (1983) Cell adhesion molecules. Science 219: 450-457. Fawcett, D. W. (1981) The Cell, W. B. Saunders Co., Philadelphia.

Flaster, M. S., E. R. Macagno, and R. S. Schehr (1982) Mechanisms for the formation of synaptic connections in the isogenic nervous sytem of Daphnia magna. In Neuronal Development, N. C. Spitzer, ed., pp. 267-296, Plenum Press, New York.

Halfter, W., D. F. Newgreen, J. Sauter, and U. Schwartz (1983) Oriented axon outgrowth from avian embryonic retina in culture. Dev. Biol. 95: 56-64.

Hasty, D. L., and E. D. Hay (1978) Freeze-fracture studies on the developing cell surface. II. Particle-free membrane blisters on glutaraldehyde-fixed corneal fibroblasts are artefacts. J. Cell Biol. 72: $758-768$.

Hinds, J. E., and P. L. Hinds (1974) Early ganglionic cell differentiation in the mouse retina: An electron microscopic analysis utilizing serial sections. Dev. Biol. 37: 381-416.

Horder, T. J., and K. A. C. Martin (1978) Morphogenelics as an alternative to chemospecificity in the formation of nerve connections. Symp. Soc. Exp. Biol. 32: 275-358.

Johns, P. R. (1977) Growth of the adult goldfish eye. III. Source of the new retinal cells. J. Comp. Neurol. 176: 343-357.

Krayanek, S., and S. Goldberg (1981) Oriented extracellular channels and axonal guidance in the embryonic chick retina. Dev. Biol. 84: $41-50$.

Lance-Jones, C., and L. Landmesser (1981a) Pathway selection by chick lumbosacral motoneurons during normal development. Proc. R. Soc. Lond. Biol. 214: 1-18.
Iance--Jones, C., and L. Landmesser (1981b) Pathway selection by embryonic chick motoneurons in an experimentally altered environment. Proc. R. Soc. Lond. Biol. 214: 19-52.

Lander, A. J., D. K. Fujii, D. Gospodarowicz, and L. F. Reichardt (1982) Characterization of a factor that promotes neurite outgrowthevidence linking activity to a heparan sulfate proteoglycan. J. Cell Biol. 94: 574-585.

Lanners, H. N., and B. Grafstein (1980) Early stages of axonal regeneration in the goldfish optic tract. An electron microscopic study. J. Neurocytol. 9: 733-751.

Letourneau, P. C. (1979) Cell-substratum adhesion of neuritic growth cones, and its role in neurite elongation. Exp. Cell Res. 124: 127138.

Letourneau, P. C. (1981) Immunocytochemical evidence for colocalization in neurite growth cones of actin and myosin and their relationship of cell-substratum adhesions. Dev. Biol. 85: 113-122.

Letourneau, P. C. (1982) Nerve fiber growth and its regulation by extrinsic factors. In Neuronal Development, N. C. Spitzer, ed., pp. 213-254, Plenum Press, New York.

McQuarrie, I. G., and R. J. Lasek (1981) Axonal transport of labeled neurofilament protein in goldfish optic axons. J. Cell Biol. Suppl. 91: 234a.

Meyer, R. L. (1978) Evidence from thymidine labeling for continuing growth of retina and tectum in juvenile goldfish. Exp. Neurol. 59: 99-111.

Morris, J. H., A. R. Hudson, and A. G. M. Weddell (1972) A study of degeneration and regeneration in the divided rat sciatic nerve based on electron microscopy. I-IV. Z. Zellforsch. 124: 76-203.

Müller, H. (1952) Bau and Wachstum der Netzhaut des Guppy (Lebistes reticulatus). Zool. Jb. (Zool. Physiol.). 63: 275-324.

Nakai, J. (1960) Studies on the mechanism determining the course of nerve fibers in tissue culture. II. The mechanism of fasciculation. $Z$. Zellforsch. 52: 427-449.

Nordlander, R. H., and M. Singer (1982a) Spaces precede axons in Xenopus embryonic spinal cord. Exp. Neurol. 75: 221-228.

Nordlander, R. H., and M. Singer (1982b) Morphology and position of growth cones in the developing Xenopus spinal cord. Dev. Brain Res. 4: $181-193$.

Nordlander, R. H., J. F. Singer, R. Beck, and M. Singer (1981) An ultrastructural examination of early ventral root formation in amphibia. J. Comp. Neurol. 199: 535-551.

Nuttall, R. P., and N. K. Wessells (1979) Veils, mounds, and vesicle aggregates in neurons elongating in vitro. Exp. Cell Res. 119: 163174.

Ogden, T. E. (1983a) Nerve fiber layer of the macaque retina: Retinotopic organization. Invest. Ophthalmol. Vis. Sci. 21: 85-98.

Ogden, T. E. (1983b) Nerve fiber layer of the owl monkey retina: Retinotopic organization. Invest. Ophthalmol. Vis. Sci. 24: 265-269.

Peters, A., and J. E. Vaughn (1967) Microtubules and filaments in the axons and astrocytes of early postnatal rat optic nerves. J. Cell Biol. 32: 113-119.

Quitschke, W., and N. Schechter (1983) Specific optic nerve proteins during regeneration of the goldfish retinotectal pathway. Brain Res. 258: 69-78.

Quitschke, W., and N. Schechter (1984) 58,000 dalton intermediate filament proteins of neuronal and non-neuronal origin in the goldfish visual pathway. J. Neurochem. 42: 569-576.

Rager, G. (1980) Development of the retinotectal projection in the chicken. Adv. Anat. Embryol. Cell Biol. 63: 1-92.

Rakić, P., and K. P. Riley (1983) Overproduction and elimination of retinal axons in the fetal rhesus monkey. Science 219: 1441-1444.

Ramón y Cajal, S. (1890) Sur l'origine et les ramifications des fibres nerveuses de la moelle embryonaire. Anat. Anz. 5: 111-119, 609-613, 631-639.

Raper, J. A., M. J. Bastiani, and C. S. Goodman (1983) Pathfinding by neuronal growth cones in grasshopper embryos. I. Divergent choices made by growth cones of sibling neurons. J. Neurosci. 3: 20-30.

Reh, T. A., E. C. Pitts, and M. Constantine-Paton (1983) The organization of the fibers in the optic nerve of normal and tectum-less Rana pipiens. J. Comp. Neurol. 218: 282-296.

Roberts, A., and B. P. Hayes (1974) A new membrane organelle in developing amphibian neurones. Cell Tissue Res. 154: 103-108.

Roberts, A., and J. S. H. Taylor (1982) A scanning electron miscroscope study of the development of a peripheral sensory neurite network. $J$. Embryol. Exp. Morphol. 69: 237-250.

Roberts, A., and J. S. H. Taylor (1983) A study of growth cones of 
developing embryonic sensory neurites. J. Embryol. Exp. Morphol. 75: $31-47$.

Rogers, S. L., P. C. Letourneau, S. L. Palm, J. McCarthy, and L. Furcht (1983) Neurite extension by peripheral and central nervous system neurons in reponse to substratum-bound fibronectin and laminin. Dev. Biol. 98: 212-220.

Rusoff, A. C., and S. S. Easter, Jr. (1980) Order in the optic nerve of goldfish. Science 208: 311-312.

Scalia, F., and V. Arango (1983) The antiretinotopic organization of the frog's optic nerve. Brain Res. 266: 121-126.

Scherer, S. S., and S. S. Easter, Jr. (1984) Degenerative and regenerative changes in the trochlear nerve of goldfish. J. Neurocytol., in press.

Scholes, J. (1979) Nerve fibre topography in the retinal projection to the tectum. Nature 278: 620-624.

Scholes, J. (1981) Ribbon optic nerves and axonal growth patterns in the retinal projection to the tectum. In Development in the Nervous System, D. R. Garrod and J. D. Feldman, eds., pp. 181-214, Cambridge University Press, Cambridge, England.

Silver, J., and R. M. Robb (1979) Studies on the development of the eyecup and optic nerve in normal mice and in mutants with congenital optic nerve aplasia. Dev. Biol. 68: 175-190.

Silver, J., and R. L. Sidman (1980) A mechanism for the guidance and topographical patterning of retinal ganglion cell axons. J. Comp. Neurol. 189: 101-111.

Stuermer, C. A. O., and S. S. Easter, Jr. (1984) Rules of order in the retinotectal fascicles of goldfish. J. Neurosci. 4: 1045-1051.

Tapscott, S. J., G. S. Bennett, Y. Toyama, F. Kleinbart, and M. Holtzer (1981) Intermediate filament proteins in the developing chick spinal cord. Dev. Biol. 86: 40-54.

Taylor, J. S. H., and A. Roberts (1983) The early development of the primary sensory neurones in an amphibian embryo: A scanning electron microscope study. J. Embryol. Exp. Morphol. 75: 4966.

Tennyson, V. M. (1970) The fine structure of the axon and growth cone of the dorsal root neuroblast of the rabbit embryo. J. Cell Biol. 44: $62-79$.

Torrealba, F., R. W. Guillery, U. Eysel, E. H. Polley, and C. A. Mason (1982) Studies of retinal representations within the cat's optic tract. J. Comp. Neurol. 211: 377-396.

Vlodavsky, I., A. Levi, I. Lax, Z. Fuks, and J. Schlessinger (1982) Induction of cell attachment and morphological differentiation of a pheochromocytoma cell line and embryonal sensory cells by the extracellular matrix. Dev. Biol. 93: 285-300.

Walls, G. L. (1963) The Vertebrate Eye and its Adaptive Radiation, pp. 559-560, Hafner, New York.

Wettstein, R., and J. R. Sotelo (1963) Electron-microscope study on the regenerative process of peripheral nerves in mice. Z. Zellforsch. 59: $708-730$.

Willard, M., and C. Simon (1981) Antibody decoration of neurofilaments. J. Cell Biol. 89: 198-205.

Witkovsky, P. (1971) Synapses mde by meylinated fibers running to teleost and elasmobranch retinas. J. Comp. Neurol. 142: 205-222.

Wolburg, H. (1980) Myelinated axons of ganglion cells in the retinae of teleosts. Cell Tissue Res. 210: 517-520.

Yamada, K. M., B. S. Spooner, and N. K. Wessells (1971) Ultrastructure and function of growth cones and axons of cultured nerve cells. J. Cell Biol. 49: 614-635. 